\title{
Research Integrity and Hidden Value Conflicts
}

\author{
Gert Helgesson ${ }^{1}$ (1) . William Bülow ${ }^{2,3}$ (])
}

Accepted: 7 December 2021 / Published online: 21 December 2021

(c) The Author(s) 2021

\begin{abstract}
Research integrity is a well-established term used to talk and write about ethical issues in research. Part of its success might be its broad applicability. In this paper, we suggest that this might also be its Achilles heel, since it has the potential to conceal important value conflicts. We identify three broad domains upon which research integrity is applied in the literature: (1) the researcher (or research group), (2) research, and (3) researchrelated institutions and systems. Integrity in relation to researchers concerns character, although it remains to specify precisely what character traits are the desirable ones in this context and what values researchers should endorse. Integrity in relation to research concerns correct and sufficient description of the research process, data, results, and overall 'research record'. Hence, it concerns the quality of research. However, whether or not this notion of research integrity covers all ethical aspects of research depends on whether one endorses a wider or a narrower interpretation of the 'research process'. Integrity in relation to research-related institutions and systems leaves open whether they should be understood as agents in their own right or merely as means to research integrity. Besides the potential lack of clarity that our analysis reveals, we point to how this variety in uses might lead to concealment of value conflicts and propose an open discussion of central values.
\end{abstract}

Keywords Ethics $\cdot$ Research ethics $\cdot$ Research integrity $\cdot$ Scientific misconduct · Terminology $\cdot$ Virtue

\section{Introduction}

Scientific misconduct and harmful research practices are drawing increasing attention among scholars and in public debate, as is the question what needs to be done to counter unethical practices and protect societal interests in adequate and useful research (Bülow \&

Gert Helgesson

gert.helgesson@ki.se

1 Stockholm Centre for Healthcare Ethics (CHE), Department of Learning, Informatics, Management and Ethics, Karolinska Institutet, Stockholm, Sweden

2 Department of Philosophy, Stockholm University, Stockholm, Sweden

3 Centre for Research Ethics and Bioethics (CRB), Department of Public Health and Caring Sciences, Uppsala University, Uppsala, Sweden 
Helgesson, 2019; Davies, 2019; Horbach \& Halffman, 2017; Steneck, 2006). More people than ever before are involved in teaching about and administration of research ethical issues, leading to a growing diversification of approaches. There is also an increasing amount of research produced on research ethics, both empirical and normative.

The issues covered in these endeavors are frequently said to concern research integrity, and, we suggest, increasingly so over the years. ${ }^{1}$ Research integrity is sometimes presented as a widely encompassing term, basically covering the entire field of research ethics, if not more (Shaw, 2019). Others suggest that research ethics and research integrity are complementing fields of inquiry, although it is not always made clear what the latter then involves. Indeed, the applications of the term research integrity are manifold. Some suggest that the term applies specifically to individual researchers, others that it concerns the research record; yet others are willing to expand the application of the term to include institutions, such as universities, but also systems that aim at ensuring good scientific practice, including public guidelines, legislation, and public authorities (Hansson, 2000; Horbach \& Halffman, 2017; Shaw, 2019; Steneck, 2006).

We suspect that some find the broadness of research integrity to be a good thing, allowing it to be sensitive to the problems and concerns of different academic, cultural, and societal contexts. Be that as it may, we believe that the disparity of uses is also potentially problematic. First, it opens up for confusion as to what is meant. For instance, does an individual researcher show integrity in relation to research in the very same regard as research legislation or research results? Are in fact different conceptions in use? Second, and more importantly, we think that the present talk about research integrity can be normatively problematic since it, at times, undermines precision and might hide important value conflicts. As we argue later in this paper, one particular scheme can promote research integrity in one sense of the word, while at the same time undermining it in another sense. Therefore, the question of whether a certain measure increases research integrity is as much a conceptual and normative question as it is an empirical one. Hence, we suggest that terminological clarifications are needed in order to better understand what is at stake in the debate and what exactly is argued for when people propose one or another scheme in order to promote research integrity. The aim of this paper is to provide such a terminological clarification and to clearly present the difficulties we identify.

We proceed as follows. We start with the question "the integrity of whom or what?" in the context of research integrity. Using the research ethical literature as guidance, three candidates are identified. We then discuss each of these candidates in somewhat greater detail and their usefulness for describing what is at stake when it comes to research integrity. Thereafter we provide some examples of how a piece of action or regulation might promote research integrity in one sense while, at the same time, decreasing it in another. This, we suggest, shows that discussions on research integrity, and especially debates on how to best promote research integrity, need to engage much more clearly in normative argumentation.

\footnotetext{
${ }^{1}$ Horbach and Halffman (2017, p. 1481) suggest that "the term 'integrity' gained currency in the scientific arena in the 1980s". Sometimes a distinction is made between scientific integrity and research integrity (e.g., Jordan, 2013; Kretser et al., 2019; Shaw, 2019). However, we leave this distinction aside here partly since we believe it to be of minor relevance to the present discussion and partly because we are not convinced that it is particularly fruitful. Another term sometimes used but not dealt with here, academic integrity (e.g., Jordan, 2013; Tauginienè et al., 2019), is partly overlapping with research integrity, but also covers appropriate conduct in education and issues of academic freedom, including how academia should protect itself from hostile infiltrators aiming to lay their hands on intellectual property.
} 


\section{Research Integrity: the Integrity of Whom or What?}

One common way of describing research integrity is to portray it as the opposite of scientific misconduct and other detrimental research practices, which are then considered breaches of integrity (see, e.g., Hansson, 2000; Steneck, 2006; Singapore Statement, 2010; Fanelli, 2011; Godecharle et al., 2013; Hiney, 2015; Meriste et al., 2016; Horbach \& Halffman, 2017). For example, Shaw and Satalkar (2018, p. 80) comment that "[m]any articles that feature integrity in their titles are really about misconduct, rather than integrity itself" (see also Titus et al., 2008). Somewhat similarly, Horbach and Halffman (2017, p. 1481) remark that "[t]he concept of 'integrity' is increasingly approached from a repressive and norm-based perspective in policy documents, stressing the need to prevent misconduct through clear rules and providing ways of sanctioning behavior that breaks these rules". Yet, Horbach and Halffman also notice a difference between positive and negative approaches, where those who endorse a positive approach of research integrity hold that research integrity amounts to more than the absence of misconduct (e.g. Science Davies, 2019; Europe, 2015; Shaw, 2019; Shaw \& Satalkar, 2018). The question then remains what this is.

One suggestion is that it is a quality that relates to individual researchers (Davies, 2019; Horbach \& Halffman, 2017; Steneck, 2006). Some even call it researcher integrity (LERU, 2020). For example, Meriste and colleagues (Meriste et al., 2016, 1.1) write that "research integrity will be understood as a researcher's commitment to professional values, which reflects in both - attitudes and actions." They point to a use where research integrity is understood as follows: "To fail to have integrity, e.g. due to falsifying or fabricating data, is to fail to be a true scientist. As such, research integrity is closely related to intellectual integrity, which concerns the commitment to truth and knowledge" (Meriste et al., 2016, Sect. 1.1.2).

However, it is sometimes suggested that research integrity also goes beyond individual researchers and research (Balmer et al., 2015; Davies, 2019; Meriste et al., 2016). For example, Shaw (2019, p. 1087; Shaw's italics) notes that "much discourse about integrity equivocates between integrity systems and structures, including guidelines and regulators, and agent integrity, or the particular qualities of people or institutions." While the 'agent integrity' concerns the individual researchers or a research group, as discussed above, our impression is that the idea that systems can have integrity is also fairly widespread. For example, in relation to research-related institutions, research integrity has been understood as "a matter of creating an environment that promotes responsible conduct" (National Academy of Sciences 2002, p. 34). Sarah Davies (2019, p. 1237) mentions "soft governance of science through codes of conduct, ELSI activities" and audit systems.

While this short exposition by no means is exhaustive, it already hints that there might be something troublesome with how the concept research integrity is being used. As remarked by Horbach and Halffman (2017), research integrity is often talked about as if referring to one and the same thing, while in fact it is applied to a wide span of things for which a "universalizing, essentialist language of "integrity" is not adequate. Referring to Guston (1999) they comment that:

...a difference in understanding of what constitutes 'integrity' reflects differing notions of what constitutes 'good science', of how this ideal should be achieved, and of how responsibilities for these issues should be shared between researchers, research institutes, research communities, and public institutions (Horbach \& Halffman, 2017, p. 1464). 
We note that it is possible to extract at least three different research-related entities or dimensions ascribed integrity from the research ethics literature: researchers, research, and research-related institutions and systems. ${ }^{2}$ The entity or dimension 'Researchers' refers to the individual researcher, or a group of researchers. In principle, it could refer to yet larger constellations of researchers as well. The principled point with this entity is that agency and responsibility can be ascribed to it. The entity 'Research' refers to the research product (results), the research process, or both of these. It can concern the integrity of a specific research report, a specific research practice, or more broadly of the research in a specific field - or in research in general. The entity 'Research-related institutions and systems', finally, refers to structures surrounding and influencing research, such as universities, funding agencies, national and international legislation, and local and national public authorities. In what follows we describe each of these three dimensions in somewhat greater detail.

\section{The Integrity of Researchers}

As noted above, one common way of understanding research integrity is that this term applies to researchers: the individual researcher, a group of researchers, or some larger constellation of researchers (Meriste et al., 2016; Shamoo \& Resnik, 2015; Shaw, 2019; Steneck, 2006). For example, ALLEA presents four fundamental principles of research integrity: reliability, honesty, respect (for colleagues, research participants, etc.), and accountability (ALLEA, 2017; cf. Meriste et al., 2016; Horbach \& Halffman, 2017). These integrity principles all clearly relate to the researcher. This understanding of research integrity is also common among researchers themselves. Sarah Davies (2019, p. 1245) summarizes parts of her findings in interviews with researchers: "There was thus a sense that the complexities of science were such that one required a strong internal compass or personal attitude of integrity; science is protected, in some way, by scientists being good people and having good intentions."

This use of research integrity fits well with one kind of definition of integrity found in dictionaries, relating to honesty, virtue, having strong moral principles that one would not back down from, and resistance to temptations and easy ways out (see for instance Cambridge Dictionary or Merriam-Webster). That said, we should note that the tendency to let integrity stand for moral character leaves it open what the appropriate values in research are. After all, saying that someone has integrity, in the sense of having strong principles and not being inclined to give in to pressure, does not necessarily mean that he has the right set of convictions (Meriste et al., 2016). For example, think of a researcher that, although strongly criticized for his way of treating research participants, does not let this criticism shake his strong conviction that the only thing a researcher has to care about is results and publications. In fact, he does not flinch an inch under the pressure from peers to improve his research practice. This researcher obviously has integrity, in one sense of the word, but it would be better if he did not, considering the values he defends. While this might seem like a somewhat silly example, it points towards a kind of problem that manifests itself also in the research ethics literature. Here you can find the position that research integrity concerns behaviour "viewed from the perspective of professional standards" (Steneck, 2006,

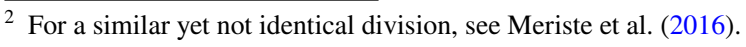


p 56; cf. Marusic et al., 2016; Kretser et al., 2019). If this is what is meant by research integrity, then the extent to which it ought to be promoted will essentially depend on the content of these professional standards. In other words, in order for research integrity to be an informative concept that can help guide policy and regulation in research, it needs to be tied to the proper set of epistemic and moral values or virtues. To this end we need to do some ethics, since we need an account of what moral values and norms research integrity ought to include. ${ }^{3}$

We should also note that it is not always clear how integrity of researchers in the sense just described relates to or promotes good research, bearing in mind the distinction between intentions, attitudes, and character on the one hand and behavior on the other. While intention is often the dividing line between carelessness and research fraud, we should be careful not to assert that researchers who are not involved in fraudulent or misleading behavior are avoiding this because they have integrity, understood in the sense of a strong inner motivation and tendency to do the right thing. They may simply have adjusted their behavior to existing conventions and incentives, such as strong social control. Instead, the relationship between research integrity - understood as involving intentions, attitudes, and character - and scientific misconduct is indirect. Researchers with strong integrity typically resist temptations to cheat, exaggerate the relevance and importance of their results, etc. But the meaning of the presently discussed understanding of research integrity is not absence of misconduct but concerns character.

To have integrity in research arguably means to stand up for research quality and the internal values of research, to be honest and transparent in one's work, and to resist temptations to take short-cuts, improve one's CV by manipulation of data or inadequate inclusion as co-author on other people's papers, etc. Such use provides the advantage of focusing on a subset of research ethical issues relating to the individual researcher, namely those relating to character. Others are left out, such as how one should reason before action or what are the right- and wrong-making characteristics of actions taken by individual researchers.

\section{The Integrity of Research}

Another way of understanding research integrity is that it is a term that applies to research, i.e., the (very) research process, research data, research results, the overall 'research record' covering all research publications, or all of these. In the words of Meriste and colleagues (2016, Sect. 1.1.1), "as a property of research findings, integrity refers to correct and reliable research results, which are not corrupted by fabrication, falsification and other similar forms of misconduct". As noted above, one common way of talking about this notion of research integrity is by referring to scientific misconduct (Fanelli, 2011; Godecharle et al., 2013; Hiney, 2015; Horbach \& Halffman, 2017; Meriste et al., 2016; Shaw \& Satalkar, 2018). Hence, to maintain the integrity of research, the scientific record should be kept uncorrupted, and this is achieved by performing research using proper methods and reporting results in a non-misleading way.

This way of talking also fits well with one of the types of definition of integrity, also found in dictionaries, where integrity is sometimes defined as soundness and the quality

\footnotetext{
${ }^{3}$ For the general point of tying integrity to the pursuit of morality, see Halfon (1989). For more detailed discussions on integrity of individuals, see McFall (1987), Fjellström (2005), and Cox et al. (2021).
} 
of being unimpaired, without any damage or mistakes (see, e.g., Merriam-Webster and Macmillan Dictionary). Absence of manipulation vis-à-vis methods and results will be one aspect of this, but there is more. Scientific ideals related to objectivity (such as intersubjectivity, intersubjective testability, universality, and completeness) seem relevant in this context as well as proper selection and application of methods for the obtainment and analysis of data (Bergström, 1972; Hanna, 2004). Norms such as openness and transparency are also instrumental to achieving an adequate research outcome through proper procedures, presented in a non-misleading and sufficiently complete way (LERU, 2020).

Although this talk of the integrity of research makes good sense, we are unsure as to what extent it adds any clarity to the discussion. We believe that we might be better off if we, instead of using the ambiguous term research integrity, were to directly discuss the various conditions that need to be in place in order to bring about correct and sufficiently described research results. Besides, since this use can be (and often is) conflated with the first use of research integrity, its use thereby sometimes decreases clarity. It is also worth noting that this notion of research integrity does not necessarily cover other ethical aspects of research, such as showing respect towards human research participants and caring for non-human animals. Rather, on this understanding the integrity of research might be intact even if the research was performed in an unethical way regarding research participants or animals used in research.

However, it is not clear that our description of the integrity of research above is exhaustive. Arguably also this more specific concept (a domain under research integrity) is ambiguous, depending on two different ways of understanding research, or research process. What is described above can be seen as a narrow interpretation. According to a wider interpretation, research (or the research process) can be understood to cover not only research activities, such as obtainment of digital data, following adequate methods in the lab, when interviewing, and when analyzing data, but also those that as a matter of fact accompany research as practiced, e.g., at our universities. This includes writing grants applications, ethics applications, and many other research-related activities that can reasonably be included in an inclusive description of "doing research". For instance, when ALLEA (2017) writes that research integrity relates not only to correctly performed research with adequately described methods and proper documentation of procedures, but also to proper protection of data, the latter arguably falls under the wider interpretation of integrity of research but not (primarily) under the narrower understanding. On this wider understanding of what is covered by the research process, the criticism that research integrity in this sense does not cover showing respect towards human research participants and caring for non-human animals no longer seems to apply.

\section{Research Integrity as an Aspect of Research-related Institutions and Systems}

It is quite often suggested that research integrity relates not only to researchers or the research they produce, but also - and sometimes in particular - to various research-related institutions and systems (National Academy of Sciences, 2002; Jordan, 2013; Meriste et al., 2016). Hence, the underlying idea is that the level of integrity of researchers and the outcome of their work at least partly has to do with the actions of university administrations, ethical review institutions, national legislation, and other regulations. For instance, Forsberg and colleagues (2018, p. 1024) state that "[r]esearchers' morals alone cannot 
ensure research integrity; good conditions for exercising integrity must also be created at the level of the organization and the research system." Similarly, Mitcham (2003) suggests that in order to promote integrity in research, individual responsibility is not enough - instead "scientists must exercise their role responsibilities collectively, through their professional societies and in collaboration with closely-linked institutions such as universities and research institutes in which they do their work, the scientific journals in which they publish, governmental bodies that support them, the media that popularize their results, and the courts that often adjudicate scientific disputes" (p. 276). One way of interpreting Mitcham is that the term research integrity should not only encompass the actions of individual researchers or the quality of the research, but should also include the whole collective effort of a range of different actors or institutions, some of which are not necessarily directly engaged in research, such as administrative personnel of universities.

One way of understanding the notion of research integrity is that institutions and systems too are agents or social actors, in the sense discussed in relation to integrity as a virtue of researchers. Even though we don't want to dismiss this possibility, we tend to think that these institutions are best understood as means of influence over something else that may or may not have integrity, while it would be less appropriate to apply the concept directly to them. Research-related institutions' greatest means of influence is through the incentives they can provide, influencing the behavior of researchers and thereby also influencing the research performance and output. Downplaying their relation to the concept of research integrity is, of course, not to downplay their potential influence over the development of research - it is, above all, a terminological issue. Much can be done to improve how research is produced and presented, and a considerable influence over this can be exerted by these institutions (see e.g. Munafò et al., 2017).

\section{How Talk of Research Integrity May Hide Value Conflicts}

So far, we have discerned three broad ways in which the notion of research integrity is used in the research ethical literature. In doing so, we have also shown that the meaning of research integrity sometimes vary and that the term might be used in a range of different ways. We suspect that quite a few readers do not find this discrepancy of uses to be much of an issue. To the contrary, they may take it to be an advantage that the concept is so flexible that it might cover all of these things the way it does. However, we believe that lack of clarity about what research integrity amounts to in a specific discussion might hide important value conflicts, and that this is something to be aware of.

For illustration, consider the claim that grave forms of scientific misconduct ought to be criminalized. Proponents of this idea often argue that this is required in order to protect and promote integrity in research (Redman \& Caplan, 2015; Sovacool, 2005). True or not, this is not merely an empirical matter, but also a conceptual and normative one. We might think that criminalization can help improving research integrity by deterring potential fraudsters. After all, less fraud may lead to more correct and reliable research results. Therefore, insofar as we with research integrity mean integrity of research, it might be true that the criminalization of grave forms of scientific misconduct increases research integrity. But once we think about other ways of using research integrity, it gets more complicated. For example, increased regulations and stricter rules of this sort may decrease the sense of personal responsibility of the individual researcher, hence threatening to decrease the integrity of researchers, understood as relating to virtue. Therefore, whether criminalization of 
scientific misconduct promotes research integrity partly depends on how research integrity is understood. Furthermore, in order to assess proposals of this sort appropriately, we also have to make normative assessments. That is, we need to say something about the value of the integrity of research and something about the value of the integrity of researchers, and what we should do if we cannot have an increase in one of them without a decrease in the other. Hence, when a new scheme has different effects in these dimensions, claims simply to the effect that 'we should increase research integrity' neither provide clear guidance nor acknowledge the need for normative assessments.

One can easily think of other examples that illustrate the risk that value conflicts get hidden under an unspecific reference to research integrity. For instance, stricter regulations regarding ethics review of research projects can be seen as strengthening research integrity, in the sense referring to research-related institutions and systems. But it is questionable whether it improves research integrity in any of the other senses. It cannot be excluded that a stricter ethics review practice reduces the proportion of inadequate research proposals that gets clearance, hence strengthening the integrity of research, but that remains to be shown. And, as noted above, increased regulation may lead to a decrease in responsibility taken by researchers. For an example with a different outcome, imagine that time-consuming interventions aiming at strengthening the integrity of researchers at universities are successful in this very regard, but take too much time and focus from learning the practical sides of data collection and analysis, leaving the quality of research in a worse state than before, hence reducing the integrity of research.

Those who endorse the concept of research integrity might respond to the problem we describe that it is a minor one and maintain that research integrity is still a helpful term. However, our point here is not that the concept is useless. Our point is rather that we should be aware that it is a concept with a wide range of uses and which as a result might hide potential value conflicts of the sort that are better brought into the light and discussed openly. What exactly do we mean by integrity in research? And what is most important, the integrity of research or the integrity of researchers (is perhaps one the goal and the other a means)? What are the values that researchers should endorse and why? These, we think, are research ethical questions that those of us who care about the integrity in research should care about.

\section{Conclusion}

Research integrity is a well-established term used to talk and write about ethical issues in research. It is sometimes presented as a widely encompassing term, basically covering the entire field of research ethics, while others suggests that research ethics and research integrity are complementary rather than overlapping. In this paper, we have identified three broad domains upon which research integrity is applied in the research ethics literature: (1) the researcher (or research group), (2) research, and (3) research-related institutions and systems. Integrity in relation to researchers concerns character. However, it remains to specify precisely what character traits are the desirable ones in this context and what values researchers should endorse. Integrity in relation to research concerns correct performance of the research and correct and sufficient description of the research process, data, results, and overall 'research record'. Hence, it can be described as concerning the quality of research. However, dependent on whether one endorses a wider or a narrower interpretation of the 'research process', it remains unclear whether this notion of research integrity 
covers all ethical aspects of research, such as the treatment of people and animals used in research. Using research integrity regarding research-related institutions and systems is not erratic, at least when looking at these as agents of their own, but we argue it is not particularly helpful either. As we have argued here, these institutions might better be seen as means to research integrity.

Taken together, our analysis reveals the ambiguity of research integrity, showing that there is a disparity of different usages, a disparity that is potentially problematic. Beside the fact that this type of ambiguity might be a source of confusion, we have argued that the variety of uses may promote misunderstanding and conceal value conflicts, which is not beneficial for an open discussion of ethical values central to research and research practice.

Authors' Contributions Both authors have contributed with ideas and arguments. GH wrote the first version of the manuscript. Both authors have revised it several times thereafter.

Funding Open access funding provided by Karolinska Institute.

Data Availability Not relevant.

Code Availability Not relevent

\section{Declarations}

Conflicts of Interest The authors declare no conflicts of interest.

Open Access This article is licensed under a Creative Commons Attribution 4.0 International License, which permits use, sharing, adaptation, distribution and reproduction in any medium or format, as long as you give appropriate credit to the original author(s) and the source, provide a link to the Creative Commons licence, and indicate if changes were made. The images or other third party material in this article are included in the article's Creative Commons licence, unless indicated otherwise in a credit line to the material. If material is not included in the article's Creative Commons licence and your intended use is not permitted by statutory regulation or exceeds the permitted use, you will need to obtain permission directly from the copyright holder. To view a copy of this licence, visit http://creativecommons.org/licenses/by/4.0/.

\section{References}

ALLEA - All European Academies. (2017). The European Code of Conduct for Research Integrity. Revised Edition.

Balmer, A. S., Calvert, J., Marris, C., Molyneux-Hodgson, S., Frow, E., Kearnes, M., Buplin, K., Schyfter, P., MacKenzie, A., \& Martin, P. (2015). Taking roles in interdisciplinary collaborations: Reflections on working in post-ELSI spaces in the UK synthetic biology community. Science \& Technology Studies, 28(3), 3-25.

Bergström, L. (1972). Objektivitet. En undersökning av innebörden, möjligheten och önskvärdheten av objektivitet $i$ samhällsvetenskapen. (Objectivity. An investigation of the meaning, possibility and desirability of objectivity in the social sciences.) Stockholm: Prisma.

Bülow, W., \& Helgesson, G. (2019). Criminalization and scientific misconduct. Medicine Health Care and Philosophy, 22, 245-252.

Cox, D., La Caze, M., \& Levine, M. Integrity. The Stanford Encyclopedia of Philosophy. Retrieved September 13, 2021, from https://plato.stanford.edu/entries/integrity/

Davies, S. (2019). An ethics of the system: Talking to scientists about research integrity. Science and Engineering Ethics, 25, 1235-1253. 
Fanelli, D. (2011). The black, the white and the grey areas: Towards an international and interdisciplinary definition of scientific misconduct. In Mayer, T and N Steneck (Eds.), Promoting research integrity in a global environment. Singapore: World Scientific Publishing, pp. 79-90.

Fjellström, R. (2005). Respect for persons, respect for integrity: Remarks for the conceptualization of integrity in social ethics. Medicine Health Care and Philosophy, 8, 231-242.

Forsberg, E.-M., Anthun, F. O., Bailey, S., Birchley, G., Bout, H., Casonato, C., Fuster, G. G., Heinrichs, B., Horbach, S., Skjæggestad Jacobsen, I., Janssen, J., Kaiser, M., Lerouge, I., van der Meulen, B., de Rijcke, S., Saretzki, T., Sutrop, M., Tazewell, M., Varantola, K., \& Zöller, M. (2018). Working with research integrity - guidance for research performing organisations: The Bonn PRINTEGER Statement. Science and Engineering Ethics, 24, 1023-1034.

Godecharle, S., Nemery, B., \& Dierickx, K. (2013). Guidance on research integrity: No union in Europe. Lancet, 381(9872), 1097-1098.

Guston, D. (1999). Between politics and science: Assuring the productivity and integrity of research. Cambridge University Press.

Halfon, M. (1989). Integrity: A philosophical inquiry. Temple University Press.

Hanna, J. F. (2004). The scope and limits of scientific objectivity. Philosophy of Science, 71, 339-361.

Hansson, M. G. (2000). Protecting research integrity. Science and Engineering Ethics, 6, 79-90.

Hiney, M. (2015). Research integrity: what it means, why it is important and how we might protect it. Science Europe. https://doi.org/10.5281/zenodo.5060050

Horbach, S. P. J. M., \& Halffman, W. (2017). Promoting virtue or punishing fraud: Mapping contrasts in the language of 'Scientific integrity.' Science and Engineering Ethics, 23, 1461-1485.

Jordan, S. R. (2013). Conceptual clarification and the task of improving research on academic ethics. Journal of Academic Ethics, 11(3), 243-256.

Kretser, A., Murphy, D., Bertuzzi, S., Abraham, T., Allison, D. B., Boor, K. J., Dwyer, J., Grantham, A., Harris, L. J., Hollander, R., Jacobs-Young, C., Rovito, S., Vafiadis, D., Woteki, C., Wyndham, J., \& Yada, R. (2019). Scientific integrity principles and best practices: Recommendations from a scientific integrity consortium. Science and Engineering Ethics, 25, 327-355.

League of European Research Universities (LERU). (2020). Towards a research integrity culture at universities: from recommendations to implementation. Advice paper No 26, Jan. 2020.

Marusic, A., Wager, E., Utrobicic, A., Rothstein, H.E., \& Sambunjak, D. (2016). Interventions to prevent misconduct and promote integrity in research and publication. Cochrane Database of Systematic Reviews 4, MR00d0038. https://doi.org/10.1002/14651858.MR000038.pub2

McFall, L. (1987). Integrity. Ethics, 98, 5-20.

Meriste, H., Parder, M.-L., Lõuk, K., Simm, K., Lilles-Heinsar, L., Veski, L., Soone, M., Juurik, M., \& Sutrop, M. 2016. Promoting integrity as an integral dimension of excellence in research. Ares 4345271.

Mitcham, C. (2003). Co-responsibility for research integrity. Science and Engineering Ethics, 9(2), 273-290.

Munafò, M. R., Nosek, B. A., Bishop, D. V. M., Button, K. S., Chambers, C. D., Percie du Sert, N., Simonsohn, U., Wagenmakers, E.-J., Ware, J. J., \& Ioannidis, J. P. A. (2017). A manifesto for reproducible science. Nature Human Behaviour, 1, 0021. https://doi.org/10.1038/s41562-016-0021

National Academy of Sciences (NAS). (2002). Integrity in scientific research: Creating an environment that promotes responsible conduct. NAS.

Redman, B. K., \& Caplan, A. L. (2015). No one likes a snitch. Science and Engineering Ethics, 21, $813-819$.

Europe, S. (2015). Briefing paper on research integrity: What it means, why it is important and how we might protect it. Science Europe.

Shamoo, A. E., \& Resnik, D. B. (2015). Responsible conduct of research. Oxford University Press.

Shaw, D. (2019). The quest for clarity in research integrity: A conceptual schema. Science and Engineering Ethics, 25, 1085-1093.

Shaw, D., \& Satalkar, P. (2018). Researchers' interpretations of research integrity: A qualitative study. Accountability in Research, 25(2), 79-93.

Singapore Statement. (2010). Available at: http://www.singaporestatement.org/ Accessed 30 April 2021.

Sovacool, B. (2005). Using criminalization and cue process to reduce scientific misconduct. The American Journal of Bioethics, 5, W1-W7. 
Steneck, N. H. (2006). Fostering integrity in research: Definitions, current knowledge and future directions. Science and Engineering Ethics, 12, 53-74.

Tauginienė, L., Gaižauskaitè, I., Razi, S., Glendinning, I., Sivasubramaniam, S., Marino, F., Cosentino, M., Anohina-Naumeca, A., \& Kravjar, J. (2019). Enhancing the taxonomies relating to academic integrity and misconduct. Journal of Academic Ethics, 17, 345-361.

Titus, S. L., Wells, J. A., \& Rhoades, L. J. (2008). Repairing research integrity. Nature, 453, 980-982.

Publisher's Note Springer Nature remains neutral with regard to jurisdictional claims in published maps and institutional affiliations. 